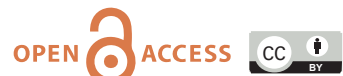

doi: 10.31729/jnma.5130

\title{
Study of Intraocular Pressure following Neodynium Yttrium Aluminium Garnet Laser Capsulotomy with the Use of Brimonidine: A Descriptive Cross-sectional Study
}

\author{
Laxmi Devi Manandhar, ${ }^{1}$ Nanda Gurung, ${ }^{2}$ Koshal Shrestha,' Binita Bhattarai,, Manita Sunam Godar,' Rahul \\ Shrestha ${ }^{2}$ \\ 'Department of General Ophthalmology, Lumbini Eye Institute and research centre, Bhairahawa, Nepal, ${ }^{2}$ Department \\ of Orthopedics, Lumbini City Hospital and Medical sciences, Butwal, Nepal.
}

\section{ABSTRACT}

Introduction: Posterior capsular opacification is a common complication after cataract surgery. Neodynium Yttrium Aluminium Garnet laser capsulotomy is still the preferred treatment for posterior capsular opacification. This study was done to determine the use of Brimonidine eye drop in preventing the rise of intraocular pressure post-Neodynium Yttrium Aluminium Garnet laser capsulotomy.

Methods: A descriptive cross-sectional study was conducted in Lumbini eye institute and research center, Bhairahawa, Nepal, in 200 eyes with posterior capsular opacification using Brimonidine from Feb 1, 2019, to July 30, 2019. The Institutional Review Committee approved the study with approval number 0237. A convenient sampling method was used. Pre-capsulotomy best-corrected visual acuity, slit-lamp examination of the anterior segment, and dilated fundus examination were done. Intraocular pressure was measured with Goldmann Applanation Tonometer. Post capsulotomy patients were evaluated after one hour, two hours, and two weeks for intraocular pressure and any complications. The statistical analysis was done using Statistical Package of Social Sciences version 20.0 statistical analysis software. The descriptive statistical analysis of the study was done after the collection of the data.

Results: Mean age of patients at presentation was 61.61 \pm SD 1.09. The mean intraocular pressure following Neodynium Yttrium aluminum garnet laser capsulotomy using brimonidine at 1 hour was $12.73 \pm 3.3 \mathrm{mmHg}$.and two hours was $11.98 \pm 3.2 \mathrm{mmHg}$. The mean energy per pulse was $2.3 \pm \mathrm{SD}$ $0.3 \mathrm{~mJ}$. The mean duration of posterior capsular opacification from cataract surgery was 22.28 weeks.

Conclusions: Neodynium Yttrium Aluminium Garnet laser capsulotomy had lower intraocular pressure after the Brimonidine eye drop procedure. The maximum mean reduction in intraocular pressure was observed after two hours.

Keywords: brimonidine; intraocular pressure; Nd:YAG laser capsulotomy.

\section{INTRODUCTION}

Posterior capsular opacification (PCO) is a frequent complication after cataract surgery. ${ }^{1}$ The standard treatment for PCO is Neodynium Yttrium Aluminium Garnet (Nd:YAG) laser posterior capsulotomy, with a more than $95 \%$ success rate. $^{2} A$ transient rise of intraocular pressure (IOP) is the most common complication following laser capsulotomy, which may occur in 15 to $36 \%$ of patients who receive no prophylactic treatment. ${ }^{3,4}$ It is due to debris deposition in the trabecular meshwork, pupillary block, and inflammatory swelling of the ciliary body or iris root

Correspondence: Dr. Laxmi Devi Manandhar, Department of General Ophthalmology, Lumbini Eye Institute and Research Center, Siddharthanagar, Bhairahawa, Nepal. Email: drlaxmi890@gmail. com, Phone: $+977-9841900142$. 
associated with angle closure. ${ }^{5}$

$\mathrm{Nd}$ :YAG capsulotomy is a common procedure done in the Lumbini eye institute. So, the study of IOP after YAG capsulotomy may provide a better concept on providing better services to patients.

This study was done to study the use of Brimonidine eye drop in preventing the rise of IOP post-Nd:YAG laser capsulotomy in a tertiary care center.

\section{METHODS}

A descriptive cross-sectional study was carried out at the outpatient department (OPD) of Lumbini eye institute and research center, Bhairahawa, Nepal, within 6 months from Feb 1, 2019 to July 30, 2019. The ethical approval committee has approved this research with approval number 0237 and the Institutional review board.

The sample size was calculated using the formula,

$$
\begin{aligned}
& \mathrm{n}=\mathrm{Z}^{2} \mathrm{p} \times \mathrm{q} / \mathrm{e}^{2} \\
& =(1.96)^{2} \times 0.5 \times 0.5 / 0.07^{2} \\
& =196 \\
& \text { Where, } \\
& \mathrm{n}=\text { required sample size } \\
& Z=1.96 \text { at } 95 \% \text { confidence interval } \\
& p=\text { prevalence } 50 \% \text { for maximum sample size } \\
& q=1-p \\
& \mathrm{e}=\text { margin of error, } 7 \%
\end{aligned}
$$

Hence, we took a sample of 200 in our study by convenient sampling method.

Inclusion criteria for enrolment were patients aged more than 20 years who underwent uneventful cataract surgery with posterior chamber intraocular lens (PCIOL) implantation with PCO. Patients diagnosed with diabetic retinopathy, retinal detachment, corneal disease, glaucoma, post trabeculectomy, uncooperative patient, and those who cannot come for follow-up and patients having PCO of fewer than three months were excluded from the study. 200 eyes who underwent Nd:YAG laser capsulotomy with the use of Brimonidine eye drop were randomly selected. Informed consent was obtained from the patients enrolled in the study.

Before performing Nd: YAG laser capsulotomy, a detailed history was taken, and a complete ocular examination was performed, including assessment of visual acuity (VA) using Snellen's vision. Slit-lamp examination of the anterior segment was done along with the status of PCIOL and PCO grading, tonometry with Goldman applanation tonometer (GAT), and dilated fundus examination. Grading of PCO was done according to The Madurai intraocular lens study IV: posterior capsule opacification. ${ }^{6}$ A grading of I to III was used to reflect the degree of opacification. The statistical analysis was done using SPSS (Statistical Package of Social Sciences) Version 20.0 Statistical Analysis Software. The descriptive statistical analysis of the study was done after the collection of the data.

\section{Procedure:}

Nd: YAG laser capsulotomy was performed in OPD as a daycare procedure by an experienced ophthalmologist. Topical Brimonidine eye drop was used in all patients one hour prior to the procedure. Post-procedure topical diclofenac four times per day for one week was prescribed to all patients. Patients were re-evaluated at one hour, two hours after the procedure and again followed up at two weeks. Examination at each subsequent evaluation included measurement of IOP using GAT, anterior chamber examination, intraocular lens (IOL), vitreous, and retina status. Any complications were noted during each follow-up. Topical Brimonidine eye drop was started in eyes with raised IOP of more than $30 \mathrm{mmHg}$.

\section{RESULTS}

Just monitoring the data of brimonidine used would be sufficient. No comparison group study is required. A total of 200 eyes of 200 patients were studied. The mean age of patients at presentation was 61.12 years \pm SD 1.29. There were $85(42.5 \%)$ male patients and $115(57.5 \%)$ female patients. The right eye is affected more than the left eye. In this study, the mean energy per shot was $2.26 \mathrm{~mJ} \pm \mathrm{SD} 0.3$ (Table 1). The mean IOP at one hour was $12.73 \pm 3.3$ and the two hours was $11.98 \pm 3.215 .47 \pm 5.0 \mathrm{mmHg}$. An increase in IOP of more than $30 \mathrm{mmHg}$ was seen in 2 patients in two hours. They were managed with topical brimonidine for one week. An increase in IOP more than $5 \mathrm{mmHg}$ after $\mathrm{Nd}$ :YAG laser posterior capsulotomy was termed as raised post-procedure IOP. Visual acuity was improved in all patients (Table 2).

PCIOL pitting $17.5 \%$ was the most common complication observed in our study. Iritis, hyphema, ruptured anterior hyaloid were also observed in our study. All patients were successfully treated. One patient who had ruptured anterior hyaloid face was treated with anterior vitrectomy (Table 3). Only two patients had an IOP rise of more than $30 \mathrm{mmHg}$. Those patients required topical anti-glaucoma (brimonidine) for 1 week.

\begin{tabular}{|lcl|}
\hline \multicolumn{3}{|c|}{ Table 1. Pre-procedure characteristics of patients. } \\
\hline $\begin{array}{l}\text { Patients } \\
\text { Characteristics }\end{array}$ & Mean $(n=200)$ & $\begin{array}{l}\text { Percentage } \\
\text { (\%) }\end{array}$ \\
$\begin{array}{l}\text { Age in years } \\
\text { Sex Male }\end{array}$ & $61.6 \pm S D 1.09$ & \\
\hline
\end{tabular}


Manandhar, et al. Study of Intraocular Pressure following Neodynium Yttrium Aluminium Garnet Laser Capsulotomy with the Use...

\begin{tabular}{|lll|} 
Female & & $115(57.5)$ \\
$\begin{array}{l}\text { Duration of PCO } \\
\text { from cataract }\end{array}$ & $22.28 \pm S D 19.46$ & \\
surgery in weeks & & \\
Energy per shots & $2.26 \mathrm{mj} \pm$ SD 0.3 & \\
Number of shots & $19.93 \mathrm{SD} \pm 8.3$ & \\
Right eye & & $110(55)$ \\
Left eye & & $90(45)$ \\
\hline
\end{tabular}

\begin{tabular}{|c|c|c|c|c|}
\hline \multirow{4}{*}{$\begin{array}{l}\text { Time intervals } \\
\text { Pre capsulotomy }\end{array}$} & \multicolumn{2}{|c|}{ IOP $\mathrm{mmHg}$} & \multirow{2}{*}{\multicolumn{2}{|c|}{$\begin{array}{c}\text { VA logmar } \\
n=200\end{array}$}} \\
\hline & & & & \\
\hline & Mean & SD & Mean & SD \\
\hline & 13.36 & 3.08 & 0.84 & 0.33 \\
\hline $\begin{array}{l}1 \text { hour post } \\
\text { capsulotomy }\end{array}$ & 12.73 & 3.3 & 0.53 & 0.30 \\
\hline $\begin{array}{l}2 \text { hours post } \\
\text { capsulotomy }\end{array}$ & 11.98 & 3.2 & 0.53 & 0.30 \\
\hline $\begin{array}{l}2 \text { weeks post } \\
\text { capsulotomy }\end{array}$ & 13.08 & 2.9 & 0.33 & 0.22 \\
\hline
\end{tabular}

\begin{tabular}{|ll|}
\hline \multicolumn{2}{|l|}{ Table 3. Complications of YAG laser Capsulotomy. } \\
\hline Complications & No. of patients $\mathrm{n}(\%)$ \\
None & $122(61.0)$ \\
PCIOL pitting & $35(17.5)$ \\
IOP rise & $2(1.0)$ \\
Iritis & $34(17.0)$ \\
Hyphema & $3(1.5)$ \\
Vitreous in anterior chamber & $1(0.5)$ \\
PCIOL subluxation & $3(1.5)$ \\
Total & $200(100)$ \\
\hline
\end{tabular}

\section{DISCUSSION}

IOP increase after $\mathrm{Nd}$ : YAG laser capsulotomy is a complication reported at various intervals. $59-67 \%$ of patients showed IOP increment of at least $10 \mathrm{mmHg}$ following Nd:YAG laser capsulotomy in the absence of anti-glaucoma prophylaxis. ${ }^{2}$ Brimonidine has been tried to decrease the rise in IOP after YAG laser capsulotomy by several researchers. ${ }^{7,8}$

In our study, the mean age at presentation was 61 yrs. This finding corresponds to the study done by Parajuli et al. and Shetty et al., which also found mean age between 50 to 70 years. ${ }^{2,9}$ This finding is due to the elderly being the most common age group undergoing cataract surgery.

A study done by Singhal et al. from India reported that raised IOP occurred after four hours of YAG laser capsulotomy where fall in 1-5 $\mathrm{mmHg}$ of IOP was seen with the use of brimonidine. ${ }^{7}$ This study also showed similar findings, but the fall in IOP was maximum in two hours. Similar to this study, Seong also found IOP decreased from the baseline by the third postoperative hour. ${ }^{10}$

Brimonidine has been proven effective to counteract the increase in IOP following Nd-YAG laser capsulotomy. Our study found that a decrease in IOP with Brimonidine after 2 hrs of YAG laser capsulotomy was by $1.4 \mathrm{mmHg}$. A study led by Yeom documented that Brimonidine $0.2 \%$ and Brimonidine Purite $0.15 \%$ have similar efficacy in the prevention of IOP elevation after Nd:YAG laser posterior capsulotomy with a decrease in IOP from baseline ranged from 2.3 to 2.7 $\mathrm{mmHg}{ }^{8}$

A study in India in 2015 showed that those patients who received more than 40 shots had a significant rise in IOP and required treatment in the form of anti-glaucoma medications immediately after the procedure for one-week post-procedure. ${ }^{9}$ Our finding was almost similar to this study. This may be explained by the energy delivered to the eye, which creates the shock waves that disturb the ciliary body or causes the neurohumoral increase in IOP.

Our study's limitation was the short duration of follow up so long-term complications could not be studied. Similarly, this study was conducted in a single tertiary care center, due to which the results cannot be generalized to all the tertiary care centers of Nepal.

\section{CONCLUSIONS}

Nd:YAG laser posterior capsulotomy is an effective and safe method for the management of posterior capsular opacification. Pre-capsulotomy Brimonidine is highly effective in controlling IOP after $\mathrm{Nd}$ :YAG laser posterior capsulotomy.

\section{Conflict of Interest: None.}

\section{REFERENCES}

1. Awasthi N, Guo S, Wagner BJ. Posterior capsular opacification: a problem reduced but not yet eradicated. Arch Ophthalmol. 2009 Apr;127(4):555-62. [ [ DOI]

2. Parajuli A, Joshi P, Subedi P, Pradhan C. Effect of Nd:YAG laser posterior capsulotomy on intraocular pressure, refraction, anterior chamber depth, and macular thickness.
Clin Ophthalmol. 2019 Jun 6;13:945-52. [ [PubMed | Full Text | DOI]

3. Achiron A. Intraocular Pressure Spikes following Neodymium-doped Yttrium Aluminium Garnet Laser Capsulotomy: Current Prevalence and Management in Israel. J Curr Glaucoma Pract. 2017 May-Aug;11(2):63-6. [PubMed | Full Text $\mid \underline{\text { DOI] }}$

4. Ge J, Wand M, Chiang R, Paranhos A, Shields MB. Long-term 
Effect of Nd:YAG Laser Posterior Capsulotomy on Intraocular Pressure. Arch Ophthalmol. 2000 Oct;118(10):1334-7. [PubMed | Full Text | DOI]

5. Karahan E, Er D, Kaynak S. An Overview of Nd:YAG Laser Capsulotomy. Med Hypothesis Discov Innov Ophthalmol. 2014;3(2):45-50. [PubMed | Full Text]

6. Prajna NV, Ellwein LB, Selvaraj S, Manjula K, Kupfer C. The madurai intraocular lens study IV: posterior capsule opacification. Am J Ophthalmol. 2000 Sep;130(3):304-9.

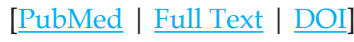

7. Singhal D, Desai R, Desai S, Shastri M, Saxena D. Use of topical brimonidine to prevent intraocular pressure elevations following Nd:YAG-laser posterior capsulotomy. J Pharmacol Pharmacother. 2011 Apr;2(2):104-6. [PubMed | $\underline{\text { Full Text | DOI] }}$
8. Yeom HY, Lee JH, Hong YJ, Seong GJ. Brimonidine $0.2 \%$ versus brimonidine Purite $0.15 \%$ : prophylactic effect on IOP elevation after Nd:YAG laser posterior capsulotomy. J Ocul Pharmacol Ther. 2006 Jun;22(3):176-81. [PubMed | Full Text | DOI]

9. Shetty NK, Sridhar S. Study of Variation in Intraocular Pressure Spike (IOP) Following Nd-YAG Laser Capsulotomy. J Clin Diagn Res. 2016 Dec;10(12):NC09-NC12. [PubMed | Full Text | DOI]

10. Seong GJ, Lee YG, Lee JH, Lim SJ, Hong YJ, Kwon OW, Kim HB. Effect of $0.2 \%$ Brimonidine in preventing intraocular pressure elevation after Nd:YAG laser posterior capsulotomy. Ophthalmic Surg Lasers. 2000 Jul-Aug;31(4):308-14. [pubMed]

This work is licensed under a Creative Commons Attribution 4.0 International License. The images or other third party material in this article are included in the article's Creative Commons license, unless indicated otherwise in the credit line; if the material is not included under the Creative Commons license, users will need to obtain permission from the license holder to reproduce the material. To view a copy of this license, visit http://creativecommons.org/licenses/by/4.0/ 